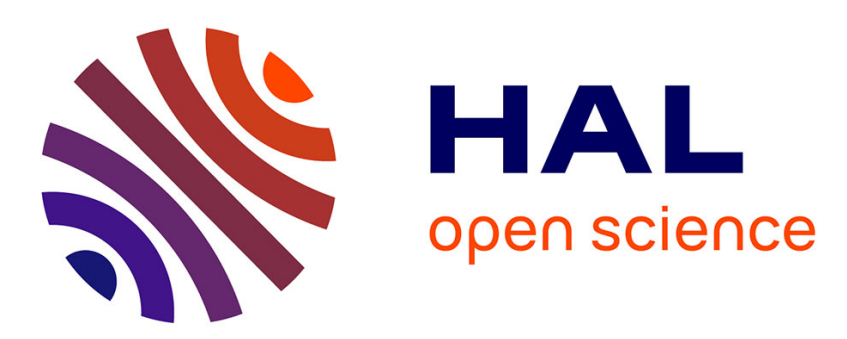

\title{
A scale-sensitive connectivity analysis to identify ecological networks and conservation value in river networks
}

K. van Looy, C. Cavillon, T. Tormos, Jeremy Piffady, P. Landry, Y. Souchon

\section{- To cite this version:}

K. van Looy, C. Cavillon, T. Tormos, Jeremy Piffady, P. Landry, et al.. A scale-sensitive connectivity analysis to identify ecological networks and conservation value in river networks. Landscape Ecology, 2013, 28 (7), p. 1239 - p. 1249. 10.1007/s10980-013-9869-x . hal-01073015

\section{HAL Id: hal-01073015 https://hal.science/hal-01073015}

Submitted on 8 Oct 2014

HAL is a multi-disciplinary open access archive for the deposit and dissemination of scientific research documents, whether they are published or not. The documents may come from teaching and research institutions in France or abroad, or from public or private research centers.
L'archive ouverte pluridisciplinaire HAL, est destinée au dépôt et à la diffusion de documents scientifiques de niveau recherche, publiés ou non, émanant des établissements d'enseignement et de recherche français ou étrangers, des laboratoires publics ou privés. 


\section{A scale-sensitive connectivity analysis to identify ecological networks and}

2 conservation value in river networks.

3 Connectivity analysis in river networks

4

5 Kris Van Looy, Cyril Cavillon, Thierry Tormos, Jérémy Piffady, Philippe Landry and Yves

\section{Souchon}

7

8 K. Van Looy (kris.van-looy@irstea.fr), National Research Institute of Science and Technology for

9 Environment and Agriculture IRSTEA Lyon, UR MALY, River hydro-ecology unit ONEMA

10 IRSTEA, 5 rue de la Doua - CS70077 - 69626 Villeurbane-Lyon cedex, France

11 C. Cavillon (cyril.cavillon@irstea.fr), National Research Institute of Science and Technology for

12 Environment and Agriculture IRSTEA Lyon

13 T. Tormos (Thierry.tormos@onema.fr), French National Agency for Water and Aquatic Environments

14 (ONEMA), River hydro-ecology unit ONEMA IRSTEA, Lyon France

J. Piffady (Jeremy.piffady@irstea.fr), National Research Institute of Science and Technology for

Environment and Agriculture IRSTEA Lyon

P. Landry (philippe.landry@oncfs.gouv.fr), National Wildlife Office (ONCFS), Research unit, 5 rue

19 Y. Souchon (Yves.souchon@ @irstea.fr), National Research Institute of Science and Technology for

20 Environment and Agriculture IRSTEA Lyon.

Keywords: Ecological Niche Factor Analysis, Integral Index Connectivity, network analysis, 
26 Existing methods for connectivity analysis still lack the accuracy required to cover both the necessary

27 resolution of explanatory factors and the dispersion events to explain functional connectivity over

28 larger territories or complex structures like dendritic river networks. To consider such relationships

29 between network structure and ecological patterns, we propose a method that allows dealing with this

30 problem of scale and resolution in the connectivity analysis of dendritic network structures, here

31 illustrated for the re-colonization of the French Loire river basin by the European otter. The ecological

32 niche factor approach is applied to infer favourable habitat in the river network based on large scale

33 data of land use and hydro-morphology of river segments for the entire river basin. Stressors to the

34 riparian zone of channel straightening, urbanisation and forest fragmentation are identified in this way

35 as the principal factors explaining otter occurrence. Based on this qualification of habitat favourability,

36 the integral index of connectivity quantifies habitat availability and connectivity in the dendritic river

37 network. When we calculate the integral index of connectivity over different spatial extents by

38 constraining network distances, the scale-sensitivity of the network's connectivity emerges. Counting

39 for high mobility (high connection distances) identifies conservation networks and priorities mainly in

40 downstream parts of the river basin, whereas zooming in on smaller network distances sorts more

41 restricted high quality areas in central and upstream parts. Finally, the presented approach performed

42 better than distribution modelling approaches in explaining species occurrence over the river network

43 and confirms the crucial aspect of connectivity in the otter re-colonization. 


\section{Introduction}

Recent theoretical and experimental studies revealed how limits in network connectivity represent key constraints for species persistence in dendritic networks (Fagan 2002; Carrara et al. 2012). In the real world this essential role of connectivity still needs to be evidenced, which is hampered by the large variation in temporal and spatial scales of analysis (Hannah 2011), and by the lack of knowledge on relationships between network structure and ecological patterns in dendritic networks (Ganio et al. 2005). The association of habitat quality and network structure with colonization processes in different settings and species is still poorly understood, but essential to prioritize conservation and restoration (Robles and Ciudad 2012; McCarthy et al. 2012; Carranza et al. 2012). For this challenge, ecological network analysis shows a remarkable expansion of methods in modelling techniques (Thuiller et al. 2009) and concepts like the integration of graph methods (Minor and Urban 2008), but little progress is made in bridging the gap between these methods and their applicability for the identification of conservation networks at large scales (Chetkiewicz et al. 2006; Laita et al. 2011; Carroll et al. 2012). Large-scale analysis for connectivity often still lacks the accuracy to integrate the relevant factors in the coarse-grained maps, and the methods covering small areas cannot be applied over larger territories (Beier et al. 2011).

To tackle this problem of scale and resolution in the design of conservation networks, we propose a scale-sensitive approach based on a connection-constrained analysis of network connectivity. We illustrate the developed approach with the distribution data of the European otter in the Loire River basin. In the last 2 decades a recovery of otter is observed for most of its West-European distribution. This recovery is recorded for Spain (Cortés et al. 1998), Italy (Loy et al. 2009) and France (Janssens et al. 2008) after many decades of decline (Lodé 1993). In the Loire river basin a core of historical population persisted and a strong re-colonization is observed (Janssens et al. 2008). We cross-examine the species' distribution with land cover and environmental variables both at the river segment and the sub-catchment scale, to identify available habitat with a graph-based method for connectivity analysis (Saura and Rubio 2010; Eros et al. 2011; Minor and Urban 2008). Quantifying available habitat and connections in networks over larger scales necessitates the integration of environmental variables at 
73 different scales (Rouget et al. 2006). The choice of target species for prioritizing conservation

74 determines the resolution of environmental data needed and the connectivity required (Arponen et al.

75 2012), both with regard to resource selection and mobility (Moilanen and Hanski 2001), as to potential

76 biotic interactions (Godsoe et al. 2012). The otter is often presented as target species and indicator for

77 the connectivity and quality of the river ecosystem (Robitaille and Laurance 2002). Population

78 dynamics of the otter plays at the river basin scale, while individuals experience the local habitat and

79 its connectivity at the river segment scale. These two scale levels are the relevant scales to gather data

80 for the assessment of river corridor quality and functions (Allan 2004; Wiens 2002).

81 In this contribution we describe the proposed method of integrated network connectivity and habitat

82 availability assessment and compare it to more commonly used distribution model approaches both in

83 its power to predict species occurrence in the river network, and to its ability to highlight the

84 contribution of connectivity in relationship to the observed ecological pattern of the otter re-

85 colonization over the river network. For this validation the importance of connectivity for otter was

86 tested in a part of the river basin where the re-colonization was fully accomplished. 


\section{Observational data for otter}

Data of otter presence was gathered in the Loire Basin by a network of associations' volunteers gathered under the Loire Basin Mammal Network, and assembled by the services of the National Wildlife Office (ONCFS). Harmonised protocols in data collection were adopted following the internationally agreed otter census protocol (Lodé 1993). For the otter, presence was confirmed from the observation of spraints (otter's droppings). The otter is a highly mobile animal with home ranges of $2-100 \mathrm{~km}$ (Ruiz-Olmo et al. 2001). In accordance to guidelines for the confirmation of otter presence and to avoid overestimating accidental visits of individuals to small water courses (Kruuk 2006), only main water courses in fluvial systems and rivers starting from a minimum catchment of $>10 \mathrm{~km}^{2}$ were retained for the analysis. As otter spraints cannot provide information on otter

100 abundance, only about presence (Mason and Macdonald 1987; Sulkava et al. 2007), and furthermore

101 the frequency of spraints may be very low when otters are at low densities (Macdonald and Mason

102 1983), the species distribution analysis was limited to a presence only approach.

103 The consistent observation effort over the last 25 years allowed for a reconstruction in well-defined

104 time-steps (5 survey periods) of otter presence and the re-colonization of the river basin. Although the re-colonization is surely not fully accomplished for the Loire basin - only 37\% of the surveyed 17 000km are occupied - the outer bounds are all reached by now (Fig. 1). And as dispersing individuals will preferably chose the best available sites as a residence, this analysis of non-fully achieved recolonization of the river network offered good perspectives to discriminate the essential factors in dispersal and habitat selection (Clavero et al. 2010; Ruiz-Olmo et al. 2001). For the analysis of the habitat selection, the presence in the most recent survey was retained (Fig. 1).

\section{Environmental and anthropogenic stressor data of the riparian corridor}

113 A systematic sectioning into river segments and assembling of hydromorphological and land cover

114 data for the riparian corridor in different buffer sizes (valley floor, floodplain, $100 \mathrm{~m}, 30 \mathrm{~m}, 10 \mathrm{~m}$ ) was

115 realised for the entire river network (Chandesris et al. 2008). Rivers were subdivided into hydro-

116 morphological units based on a semi-automatic sectioning that distinguished changes in geological 
117 entities, channel form, sinuosity and valley floor width. Resulting river segments range from $1 \mathrm{~km}$ on

118 average for small streams and up to $20 \mathrm{~km}$ on average for large rivers. For each of these river

119 segments, information was collected from two spatial scales: the catchment's land cover information

120 was gathered for regional sub-catchments (i.e. hydrological units delimited by water divides and river

121 confluences) and locally information on land cover and hydromorphology was extracted for the

122 individual river segment in different dimensions for the riparian corridor (Table 1).

123

\section{Ecological niche factor network analysis}

125 The restriction to presence only data was the reason to apply the ecological niche factor analysis

126 (ENFA) in the definition of ecological networks for the species (Hirzel et al. 2001). This method also allowed inferring key habitat factors from incomplete distribution data as was obviously the case for this colonizing species' distribution (Clavero et al. 2010). ENFA allowed integrating the inferred habitat factors in a network analysis to mark the potential network occupied by the species (Basille et al. 2009). The marginality and specialisation of the species' presences was determined for the

131 environmental variables over the river segments to describe the ecological niche of the species. The $95 \%$ confidence intervals of the variables with significant marginality and specialisation for occupied segments were selected as boundary values to consider segments as favourable. An extrapolation of this ecological niche over the entire river basin was carried out. Distance criteria were applied to join

135 favourable segments based on the minimum home range values of $2 \mathrm{~km}$ for otter, and this resulted in 136 networks of non-fragmented habitat patches over the river basin.

\section{Ecological network design based on connectivity analysis}

139 The dendritic river network structure needed an adequate topological definition for the analysis of its 140 potential as ecological network for the species (Grant et al. 2007). For this purpose and in agreement 141 with terrestrial network frameworks, the river segments were regarded as habitat nodes whereas the

142 true river network nodes (confluences and segment junctions) were considered as connectors in the

143 network (Eros et al. 2011). As we investigated species movement both in up- and downstream

144 direction, the full complexity of dendritic networks came in the picture. Starting from the topological 
145 definition of the river segments in GIS, scripts were developed to derive neighbourhood matrices that

146 depicted the network structure. Figure 2 illustrates the resulting network structure that was applied in

147 the analysis.

148 We adopted the graph method of weighing network importance of nodes (Urban 2005), defined as

149 river segments in our case, by a specified application of the Integral Index of Connectivity (Pascual-

150 Hortal and Saura 2006). This index offered a measure that integrates the habitat quality of nodes with

151 the complexity and connectivity of the landscape. For our specific river network implementation,

152 integrating the habitat suitability output of the ENFA, the general formula of the Integral Index of

153 Connectivity was defined as follows:

$154 \quad \mathrm{IIC}=\Sigma_{\mathrm{i}} \Sigma_{\mathrm{j}}\left[\right.$ favourability $_{\mathrm{i}} \mathrm{x}$ favourability $\left.\mathrm{j} /\left(1+\mathrm{nl}_{\mathrm{ij}}\right)\right] / \mathrm{A}_{\mathrm{L}}^{2}$

156 With $A_{L}$ the overall sum of favourability for all the segments of the entire river basin, and $\mathbf{n l}_{\mathbf{i j}}$ the

157 number of segments between segments $\mathrm{i}$ and $\mathrm{j}$, as connection distance present in the neighbourhood

158 matrix. The overall index ranges from 0 to 1 and increases with improved connectivity (Pascual-Hortal

159 and Saura 2006, 2008). The relative ranking of segments by their contribution to the overall index

160 value is the individual segment's qualification that is useful in this conservation approach. To

161 calculate the importance of each individual segment, we systematically removed each particular

162 segment and recalculated the IIC index. The percentage of index value loss (delta value dIIC)

163 measured the contribution of each segment to the overall index value (Pascual-Hortal and Saura 2008).

164 This dIIC can be considered a habitat availability index (Pascual-Hortal and Saura 2006). We

165 used the recently developed Conefor Sensinode 2.2 software (Saura and Torné 2009) to calculate dIIC

166 values for each river segment.

168 Constraining the connection distance $\mathbf{n n}_{\mathbf{i j}}$ of number of segments, and thus the extent of the

169 neighbourhood matrix, allowed a scale-sensitive calculation of the index. With connection distance 0 ,

170 no integration took place of connectivity and habitat quality of the surrounding segments. In this way,

171 the classical habitat network analysis was performed as described above, based on local habitat 
172 quality. For a connection distance of 2 and 5, local network structure integrating the habitat quality of

173 the segments was considered. With regard to the otter's home range this measure of 2 to 5

174 neighbouring segments corresponded to a relevant ecological network scale level covering river

175 lengths from 5 up to $100 \mathrm{~km}$, which was in agreement with the species' home range. To infer the scale-

176 sensitivity of this network qualification approach, the calculation was also performed with

177 constraining connection distances to 10.

178

\section{Validation importance of connectivity}

180 To evaluate the merits of the proposed connectivity analysis, its outcome was compared to both the

181 ENFA approach described above and more dynamic distribution modelling approaches. We generated

182 five different data sets for this comparison. One set consisted of the presence-absence data directly.

183 Four other sets are probabilities of occurrence, generated with respectively the ENFA, a logistic

184 regression and the IIC with connection distances 2 and 5.

185 The dynamic logistic regression model was obtained from the otter presences over the five surveys.

186 The determining habitat factors detected with ENFA were entered in a logistic regression model to

187 derive a colonization likelihood estimate. For each time step (5 steps of 5 year) the neighbouring river

188 segments at the colonization front were simulated and confronted with the observed progression. With

189 this model probability of occurrence was inferred over the entire river network, and confronted with

190 the results of the other analyses for occurrence probability. For this comparison correlations were

191 tested for the river segments of the entire river network between the modelled ENFA habitat

192 favourability, the regression model occurrence probability and the integrated connectivity measures.

193 Afterwards, the model results were confronted with the recorded colonization process for the fully-

194 colonized upstream part of the basin, based on the detailed dataset of the regional nature park of the

195 Livradois-Forez (PNRLF). A measure of colonization speed for the PNRLF river network was

196 calculated over the three recent time steps in which the re-colonization took place: 1995-1999, 2000-

197 2004, and 2005-2009. Each newly occupied river segment was attributed a value of colonization

198 speed, by counting the number of segments traversed at first occurrence to the nearest previously 
199 occupied segment. Correlation of the different model outputs to this colonization speed over the

200 PNRLF river network finally revealed the best predictor of otter occurrence.

201 


\section{Results}

\section{Species niche}

204 Only 5 out of 22 environmental variables showed discriminating scores in the analysis of marginality and specialisation (Fig. 3). The strongest explaining factor for species presence was the rate of channel normalization ('channel straightening') with significant marginality and specialisation $(\mathrm{M}=0.12, \mathrm{~S}=$ 1.16). This factor showed in the niche factor analysis the highest discriminating power on the river network, as it qualifies $12 \%$ of the river segments as unfavourable. Strong marginality with little specialisation though is observed for the forest cover in the floodplain $(\mathrm{M}=-0.13, \mathrm{~S}=0.97)$ and in the $30 \mathrm{~m}$ buffer $(\mathrm{M}=-0.16, \mathrm{~S}=0.96)$. Urbanisation in the $100 \mathrm{~m}$ buffer showed a high specialisation $(\mathrm{S}=1.17)$ that allows a discrimination of $6 \%$ of the river basin's segments as unfavourable in the niche factor analysis due to urbanization pressure in the river corridor. The favourable river segments represent for the otter in the Loire basin $82 \%$ of the 17 000km selected river length (Fig. 4). Where

214 favourable conditions can be found in all parts of the basin, the most unfavourable conditions are 215 concentrated in the downstream part of the river basin.

\section{Network analysis}

218 The network analysis based on local habitat, without connectivity integration, determined with ENFA as favourable segments joined to ecological networks (Fig. 5a), results in 452 patches of linked

220 favourable segments over the basin with a mean length of $29.3 \mathrm{~km}$ but high variability $(\mathrm{sd}=62.1 \mathrm{~km})$

221 and a dominance of smaller patches. The longest favourable patches $(\max =590.2 \mathrm{~km})$ are mainly

222 situated along the middle sectors of the main rivers Loire and Allier.

223 The network connectivity analysis based on the dIIC-connection distance 5 (Fig. 5b) shows a different 224 picture. The favourable networks in the centre of the basin (for the main rivers of Loire and Allier and the south-western sub-catchment of the Vienne-Creuse) are also highlighted, but in this analysis the

226 lower parts of the basin are identified as most important in the river network.

\section{Scale-sensitivity of the method}


229 Constraining the neighbourhood matrix up to the second neighbours (dIIC_2) allows identifying

230 networks based on local habitat availability (Fig. 6). This result shows a higher differentiation at the

231 local scale level. It differs from the network qualification based solely on the individual segment

232 quality (Fig. 5a) as it integrates the favourability of the local network. It differs also from the larger

233 scale connectivity analysis (Fig. 5b) as it reflects more strongly the local habitat availability, but not so

234 much the larger scale network structure of the dendritic river network. With a higher connectivity of

235 connection distance 10, the effect of local habitat availability gets completely lost for our studied

236 network structure and only the overall river basin connectivity is highlighted with dIIC values

237 gradually increasing from upstream to downstream.

\section{Connectivity validation}

239 The logistic regression model predicted the likelihood of colonization accurately in $35 \%$ of the cases.

240 Its modelled occurrence probability over the entire river basin showed a negative correlation with the

241 dIIC_5 $(\mathrm{R}-0.046, \mathrm{p}<0.05)$ and a positive correlation with dIIC_2 $(\mathrm{R} 0.14, \mathrm{p}<0.05)$. For the 1501

242 segments in the upstream PNRLF-region, the modelled occurrence probability showed a positive

243 correlation with both the dIIC_5 (R 0.2, p<0.001) and with the dIIC_2 (R 0.23, p<0.001). Still these

244 correlations are quite weak and so the question remains for otter occurrence being more explained by

245 local habitat factors than by connectivity.

246 For the PNRLF-region, colonization speed of the occupied segments was between 1 and 16, with an

247 average of 3 . This colonization speed of the segments was marginally correlated to the results of the

248 static ENFA favourability $(\mathrm{R} 0.21, \mathrm{p}<0.05)$ and of the dynamic logistic regression modelled

249 occurrence probability $(\mathrm{R} 0.19, \mathrm{p}<0.05)$. Much stronger correlation was observed for the connectivity

250 measure of the dIIC_2 $(\mathrm{R} 0.52, \mathrm{p}<0.001)$. The higher scale connectivity measure dIIC_5 on the

251 contrary shows a negative correlation $(\mathrm{R}-0.17, \mathrm{p}<0.05)$.

\section{Discussion}

\section{Integrated approach to network connectivity analysis}

255 The presented approach adopts the recent developments in river ecology of graph based methods (Eros 256 et al. 2011) and connectivity loss weighing (Moilanen et al. 2008; Hermoso et al. 2011). Yet, it differs 
from existing connectivity analysis methods to prioritize conservation networks in its integrative quantification of habitat availability and connections in the network. Furthermore, by integrating all branches and connections in the neighborhood matrices we shifted from a linear to a branched river network connectivity analysis (Fisher 1997; Grant et al. 2008). All neighbouring segments along the branches of the dendritic network both in downstream as upstream direction are embedded in this quantification. They are weighed by distance and constrained by a distance criterion to allow a scalesensitive analysis. So, although it does not provide a method that weighs up specific trajectories and connections (Carroll et al. 2012), we do accomplish the main objective for the analysis of networks, that is to quantify connectivity in relationship with the ecological processes within the network. Most recently developed connectivity measures - even those adjusted to river networks - only count for a distance criterion of connections (Hermoso et al. 2011; Moilanen et al. 2008). In contrast to this strong distance-based interpretation and the barrier emphasis of the least-cost path approaches (Pinto and Keitt 2009; Morzillo et al. 2011), we incorporate the evaluation of the branch density of the dendritic structure in the network analysis (Ganio et al. 2005), with the IIC that measures the density of connectors, that is the 'branchiness' of the river network in our example. River segments are evaluated at the same time as habitat and as connectors in our approach; which is a strong point in the conservation context of ecological networks. In this way, the IIC is generally considered a habitat availability index (Pascual-Hortal and Saura 2006) because it integrates topological properties (network connectivity) with habitat quantity.

\section{Scale-sensitive ecological network analysis}

The scale-sensitive integration of river segment length and resolution of the network under study is in accordance to species behaviour (Baguette and Vandyck 2007) and is the basis for the aggregation of the local habitat with the connectivity over the drainage basin, a necessary step in ecological network analyses for the otter (Ottaviani et al. 2009). This scale-sensitive approach demands the acquisition of

282 environmental variables from different scales according to the network structure. Most species

283 distribution studies at large scale start from raster-based landscape representations and metrics

284 (Barbosa et al. 2001, 2003; Loy et al. 2009; Clavero et al. 2010) that do not allow interpretation of 
data gathered at multiple scales to the dendritic network. Only recently the geometric network

analysis has been developed with the graph methods (Urban and Keitt 2001; Jordán et al. 2003). The

presented integration of scale-sensitivity by confining the extent of connections allows the

prioritization of conservation networks based on specific objectives, like sets of target species or ecosystem processes and functions with specific spatial demands.

290 The presented case study shows some restrictions for the attribution of habitat quality to the

291 observations as the data of otter occurrence only allowed for a presence-only approach with its

292 weaknesses (Tsoar et al. 2007). Still we believe this dataset for the Loire basin is one of the best

293 documented examples of otter colonization globally, especially in view of its time span and the size of

294 the basin. The unique large scale dataset on environmental quality of the riparian zones proved appropriate to infer the relevant ecological factors in the colonization process. Restrictions of this environmental dataset concern aspects of water quality, food resources and the height of dams and dikes. Yet, from earlier analyses in the Loire basin no relationship between otter expansion and water quality, prey abundance or fish community could be inferred (Lemarchand et al. 2007; Janssens et al. 2008), neither proved the height of dams a significant obstacle to the species' progress (Varray 2011).

Therefore and also based on the limited data at hand for these variables, we did not include them in the analysis.

The ecological potentials and targets for the river system in question will determine the scale of

303 connectivity to incorporate in the designation of conservation priorities. In our case for the Loire River

304 basin, a well-preserved aquatic biodiversity together with a high potential for conservation and

305 restoration of mobile riverine species like otter, beaver, salmon, sturgeon, osprey and river terns, calls

306 for the larger scale connectivity approach and identifies priorities principally in the downstream 307 reaches.

\section{Connectivity in river networks}

310 Our results confirm the conclusions of Moilanen and colleagues that realistic modelling of

311 connectivity has a major influence on the areas proposed for conservation, pointing out different parts

312 of river basins as high priority conservation targets (Moilanen et al. 2008). Same as several other 
recent publications (Carranza et al. 2012; Hermoso et al. 2012), we supply evidence and methods to

314 integrate different scales and dimensions in connectivity measures, although not focussed on inter-

315 basin connectivity as these authors. The proposed method for the integrated connectivity measure

316 proves even more accurate in predicting species occurrence than the dynamic probability modelling

317 that sorted as best available method from earlier comparisons (Van Teeffelen, 2006).

319 The more classical habitat-based network analysis corresponds to the result without node network

320 connections $\left(\mathrm{nl}_{\mathrm{ij}}=0\right)$ in our approach. This result clearly deviates from the results with integration of

321 functional connections. For the analysis of ecological networks for the otter the local network-

322 focussed dIIC_2 provides the most accurate predictor for otter occurrence probability. Still, for the

323 long time population expansion and survival, as well as for the conservation prioritization, the dIIC_5

324 surely brings important additional information as well. The comparison to the observed colonisation

325 speed in the upstream part of the basin shows that the dIIC_5 measure is probably not the best

326 predictor for otter colonisation, but it might well be the best prospection for an ecological network to

327 assure otter survival in the long run. This assumption of course needs another type of analysis, or a

328 repeated analysis by the time the colonisation process is fully accomplished over the river basin. The

329 validation of the connectivity analysis with the comparison to the static and dynamic distribution

330 modelling approaches, showed the strength of our approach as it predicted better the otter

331 colonization. Where our approach starts from a static distribution modelling approach, this result

332 proves the strength of the proposed approach, as it even gives a better result than the dynamic habitat-

333 based colonization model that is based on the extended dataset on otter presence over time in the river

334 basin. We didn't integrate this more dynamic distribution model in the proposed method for

335 connectivity analysis, as obviously such a dynamic model needs to be based on temporally explicit

336 data and an exceptionally rich dataset as presented here is mostly not available.

338 In conclusion we can say that the presented method meets our goal to quantify connectivity in the river

339 network, considering both the complexity of the dendritic network structure and the scale-sensitivity

340 of relationships between network structure and ecological patterns in rivers. It even showed more 
341 reliable results in predicting species colonization in the network than distribution modelling

342 techniques. The outcome proves the importance of connectivity for the otter, as the movement and

343 occurrence in the river network was more explained by connectivity measures than just with habitat

344 quality aspects. In this way it confirms the otter as a guiding species for connectivity and not solely

345 for habitat quality.

346 With the presented method insight can be gained into the choices for river restoration and conservation

347 prioritization. Allocation of financial resources for conservation and restoration can be based on this

348 kind of analyses with the integration of multi-species approaches (Schwenk and Donovan 2011).

349 Cross-examining resulting ecological networks for multiple species with multiple relevant scales for

350 connectivity can reveal priorities for conservation (Williams et al. 2005). The here presented approach

351 can also be used for fully aquatic species in river systems with integration of flow-directed

352 connectivity.

353

354 Acknowledgments

355 This work was only possible thanks to the strong observation effort of the volunteers of the Loire

356 Basin Mammal Network and the agents of the National Wildlife Office (ONCFS) since 1985. Nadine

357 Nogaret of the Regional Nature Parc of the Livradois-Forez provided detailed information on the

358 species' re-colonization. The river data collection in the hydro-morphology audit system SYRAH is

359 financed by the French Ministry of Research and the Ministry of Environment and Sustainable

360 Development. We are indebted to Sandrine Ruette (ONCFS) and Charles Lemarchand (University

361 Clermond-Ferrand) for their constructive comments on the analysis approach and interpretation of the

362 species' inventories. The editor and two anonymous reviewers offered useful suggestions to improve

363 the manuscript.

365 References

366 Allan JD (2004) Landscapes and Riverscapes: The Influence of Land Use on Stream Ecosystems. Ann 
Arponen A, Lehtomäki J, Leppänen J, Tomppo E, Moilanen A (2012) Effects of Connectivity and Spatial Resolution of Analyses on Conservation Prioritization across Large Extents. Conserv Biol 26:294-304

Baguette M, Van Dyck H (2007) Landscape connectivity and animal behavior: functional grain as a key determinant for dispersal. Landscape Ecol 22:1117-1129

Barbosa AM, Real R, Marquez AL, Rendon MA (2001) Spatial, Environmental and Human Influences on the Distribution of Otter (Lutra lutra) in the Spanish Provinces. Diversity and Distributions 7:137-144

Barbosa AM, Real R, Olivero J, Vargas JM (2003) Otter (Lutra lutra) distribution modeling at two resolution scales suited to conservation planning in the Iberian Peninsula. Biol Conserv $114: 377-387$

Basille M, Herfindal I, Santin-Janin H, Linnell JDC, Odden J, Andersen R, Hogda KA, Gaillard J-M (2009) What shapes Eurasian lynx distribution in human dominated landscapes: selecting prey or avoiding people? Ecography 32:683-691

Beier P, Spencer W, Baldwin RF, Mcrae BH (2011) Toward Best Practices for Developing Regional Connectivity Maps. Conserv Biol 25:879-892

Carranza ML, D'alessandro E, Saura, S, Loy A (2012) Connectivity providers for semi-aquatic vertebrates: the case of the endangered otter in Italy. Landscape Ecol 27:281-290

Carrara F, Altermatt F, Rodriguez-Iturbe I, Rinaldo A (2012) Dendritic connectivity controls biodiversity patterns in experimental metacommunities. Proceedings of the National Academy of Sciences doi/ 10.1073/pnas.1119651109

Carroll C, Mcrae BH, Brookes A (2012) Use of Linkage Mapping and Centrality Analysis Across Habitat Gradients to Conserve Connectivity of Gray Wolf Populations in Western North America. Conserv Biol 26:78-87

Chandesris A, Mengin N, Malavoi JR, Wasson JG, Souchon Y (2008) SYRAH-CE: SYstème Relationnel d'Audit de l'Hydromorphologie des Cours d'Eau A relational, multi-scale system for auditing the hydro-morphology of running waters: diagnostic tool to help the WFD 
implementation in France. In: Proceedings of the 4th international conference on river restoration, Venice, ITA, 16-21 June 2008. Eds. Gumiero B, Rinaldi M, Fokkens B. 4p.

Chetkiewicz C, St. Clair C, Boyce M (2006) Corridors for Conservation: Integrating Pattern and Process. Ann Rev Ecol Evol Syst 37:317-342

Clavero M, Hermoso V, Brotons L, Delibes M (2010) Natural, human and spatial constraints to expanding populations of otters in the Iberian Peninsula. J Biogeography 37:2345-2357

Cortés Y, Fernández-Salvador R, García FJ, Virgós E, Llorente M (1998) Changes in otter Lutra lutra distribution in Central Spain in the 1964-1995 period. Biol Conserv 86:179-183

Eros T, Schmera D, Schick RS (2011) Network thinking in riverscape conservation - A graph-based approach. Biol Conserv 144:184-192

Fagan WF (2002) Connectivity, fragmentation, and extinction risk in dendritic metapopulations. Ecology 83:3243-49

Fisher SG (1997) Creativity, idea generation, and the functional morphology of streams. Journal of the North American Benthological Society 16:305-318

Ganio LM, Torgersen CE, Gresswell RE (2005) A geostatistical approach for describing spatial pattern in stream networks. Frontiers in Ecology and the Environment 3:138-144

Godsoe W, Harmon LJ (2012) How do species interactions affect species distribution models? Ecography 35:811-820

Grant EHC, Lowe WH, Fagan WF (2007) Living in the branches: population dynamics and ecological processes in dendritic networks. Ecology Letters 10:165-175

Hannah LEE (2011) Climate Change, Connectivity, and Conservation Success. Conserv Biol, $25: 1139-1142$

417 Hermoso V, Linke S, Prenda J, Possingham HP (2011) Addressing longitudinal connectivity in the systematic conservation planning of fresh waters. Freshw Biol 56:57-70

419 Hermoso V, Kennard MJ, Linke S (2012) Integrating multidirectional connectivity requirements in systematic conservation planning for freshwater systems. Diversity and Distributions 
Hirzel AH, Hausser J, Chessel D, Perrin N (2001) Ecological-niche factor analysis: how to compute habitat-suitability maps without absence data? Ecology 83:2027-2036

Janssens X, Fontaine MC, Michaux JR, Libois R, De Kermabon J, Defourny P, Baret PV (2008) Genetic pattern of the recent recovery of European otters in southern France. Ecography 31:176-186

Jordán F, Báldi A, Orci KM, Rácz I, Varga Z (2003) Characterizing the importance of habitat patches and corridors in maintaining the landscape connectivity of a Pholidoptera transsylvanica (Orthoptera) metapopulation. Landscape Ecol 18:83-92

Kruuk H (2006) Otters, Ecology, Behaviour and Conservation. Oxford University Press Inc., New York

Laita A, Kotiaho JS, Monkkonen M (2011) Graph-theoretic connectivity measures: what do they tell us about connectivity? Landscape Ecol 26:951-967

Lemarchand C, Amblard C, Souchon Y, Berny P (2007) Organochlorine compounds (pesticides and PCBs) in scats of the european otter (Lutra lutra) from an actual expanding population in central france. Water Air and Soil Pollution 186:55-62

Lodé T (1993) The decline of otter Lutra lutra populations in the region of the pays de loire, Western France. Biol Conserv 65:9-13

Loy A, Carranza ML, Cianfrani C, D'Alessandro E, Bonesi L (2009) Otter Lutra lutra population expansion: assessing habitat suitability and connectivity in southern Italy, Folia Zoologica $58: 309-326$

MacDonald S, Mason C (1983) The otter Lutra lutra in Southern Italy. Biol Conserv 25:95-101

Mason CF, Macdonald S (1987) Otters: ecology and conservation. Cambridge University Press, Cambridge

Mccarthy KP, Fletcher Jr RJ, Rota CT, Hutto RL (2012) Predicting Species Distributions from Samples Collected along Roadsides. Conserv Biol 26:68-77

Minor ES, Urban DL (2008) A Graph-Theory Framework for Evaluating Landscape Connectivity and Conservation Planning. Conserv Biol 22:297-307 
Moilanen A, Hanski I (2001) On the use of connectivity measures in spatial ecology. Oikos 95:147-

450

\section{1}

Moilanen A, Leathwick J, Elith J (2008) A method for spatial freshwater conservation prioritization. Freshw Biol 53:577-592

Morzillo A, Ferrari J, Liu J (2011) An integration of habitat evaluation, individual based modeling, and graph theory for a potential black bear population recovery in southeastern Texas, USA. Landscape Ecol 26:69-81

Ottaviani D, Panzacchi M, Lasinio G.J, Genovesi P, Boitani L (2009) Modelling semi-aquatic vertebrates' distribution at the drainage basin scale: The case of the otter Lutra lutra in Italy, Ecological Modelling 220:111-121

Pascual-Hortal L, Saura S (2006) Comparison and development of new graph-based landscape connectivity indices: towards the priorization of habitat patches and corridors for conservation. Landscape Ecol 21:959-967

Pascual-Hortal L, Saura S (2008) Integrating landscape connectivity in broad-scale forest planning through a new graph-based habitat availability methodology: application to capercaillie (Tetrao urogallus) in Catalonia (NE Spain). European Journal of Forest Research 127:23-31

Pinto N, Keitt TH (2009) Beyond the least-cost path: evaluating corridor redundancy using a graphtheoretic approach. Landscape Ecol 24:253-266

Robitaille JF, Laurance S (2002) Otter, Lutra lutra, occurence in Europe and in France in relation to landscape characteristics. Anim Conserv 5:337-344

Robles H, Ciudad C (2012) Influence of Habitat Quality, Population Size, Patch Size, and Connectivity on Patch-Occupancy Dynamics of the Middle Spotted Woodpecker. Conserv Biol 26:284-293

Rouget M, Cowling RM, Lombard AT, Knight AT, Kerley GIH (2006) Designing Large-Scale Conservation Corridors for Pattern and Process. Conserv Biol 20:549-561

Ruiz-Olmo J, Saavedra D, Jiménez J (2001) Testing the surveys and visual and track censuses of Eurasian otters (Lutra lutra). Journal of Zoology 253:359-369 
Saura S, Rubio L (2010) A common currency for the different ways in which patches and links can contribute to habitat availability and connectivity in the landscape. Ecography 33:523-537

Saura S, Torné J (2009) Conefor Sensinode 2.2: a software package for quantifying the importance of habitat patches for landscape connectivity.

Schwenk WS, Donovan TM (2011) A Multispecies Framework for Landscape Conservation Planning. Conserv Biol 25:1010-1021

Sulkava R, Sulkava P, Sulkava P (2007) Source and sink dynamics of density-dependent otter (Lutra lutra) populations in rivers of central Finland. Oecologia 153:579-588

Thuiller W, Lafourcade B, Engler R, Araújo MB (2009) BIOMOD - a platform for ensemble forecasting of species distributions. Ecography 32:369-373

Tsoar A, Allouche O, Steinitz O, Rotem D, Kadmon R (2007) A comparative evaluation of presenceonly methods for modelling species distribution. Diversity \& Distributions 13:397-405

Urban DL (2005) Modeling ecological processes across scales. Ecology 86:1996-2006

Urban DL, Keitt T (2001) Landscape connectivity: A graph-theoretic perspective. Ecology 82:12051218

Van Teeffelen AJA, Cabeza M, Moilanen A (2006) Connectivity, probabilities and persistence: Comparing reserve selection strategies. Biodiv and Conserv 15:899-919

Varray S (2012) Etude des continuités écologiques du castor et de la loutre sur le bassin de la Loire : analyse de la franchissabilité des obstacles à l'écoulement. ONCFS, Paris 37 p.

Wiens JA (2002) Riverine landscapes: taking landscape ecology into the water. Freshw Biol 47:501515

Williams P, Hannah L, Andelman S, Midgley G, Araujo M, Hughes G, Manne, L, Martinez-Meyer E, Pearson R (2005) Planning for climate change: Identifying minimum-dispersal corridors for the Cape proteaceae. Conserv Biol 19:1063-1074 
501 Table 1. Environmental variables from the different spatial scales that were attributed to the river

502 segments.

\section{Watershed}

urbanisation

intensive agriculture

Natural

\section{River segment}

Altitude
river slope
valley slope
Discharge
Sinuosity
channel straightening
density of bars
density of weirs/dams
density of bridges

Alluvial plain alluvial forest cover Infrastructure urbanisation density of dikes connected waters Disconnected waters

\section{River bank}

riparian forest cover riparian forest canopy Infrastructure urbanisation percentage cover of urban land use class in CORINE land cover data of the sub-catchments percentage cover of intensive agricultural CORINE land cover classes of the sub-catchments percentage cover of near-natural CORINE land cover classes data of the sub-catchments

elevation at downstream point of river segments

slope of the river bed over the segment

valley slope perpendicular to the river

mean annual discharge for gauging station or model prediction at river segment level sinuosity of the river bed over the segment

percentage of straight reaches over the segment, weighted by river type number of lateral bars over the segment, divided by river length

number of weirs/dams per segment, divided by river length number of river crossing bridges per segment, divided by river length

percentage cover of forest patches over the alluvial plain of the river segment percentage cover of infrastructure over the alluvial plain of the river segment percentage cover of urbanisation over the alluvial plain of the river segment length of flood protection levees per segment, divided by river length percentage cover of connected standing waters over the alluvial plain of the river segment percentage cover of disconnected standing waters over the alluvial plain of the river segment

percentage cover of forest patches for the 30m riparian buffer of the river segment percentage cover of forest patches for the $10 \mathrm{~m}$ riparian buffer of the river segment percentage cover of infrastructure over riparian buffer of three river widths of the segment percentage cover of urbanisation for the $100 \mathrm{~m}$ riparian buffer of the river segment 


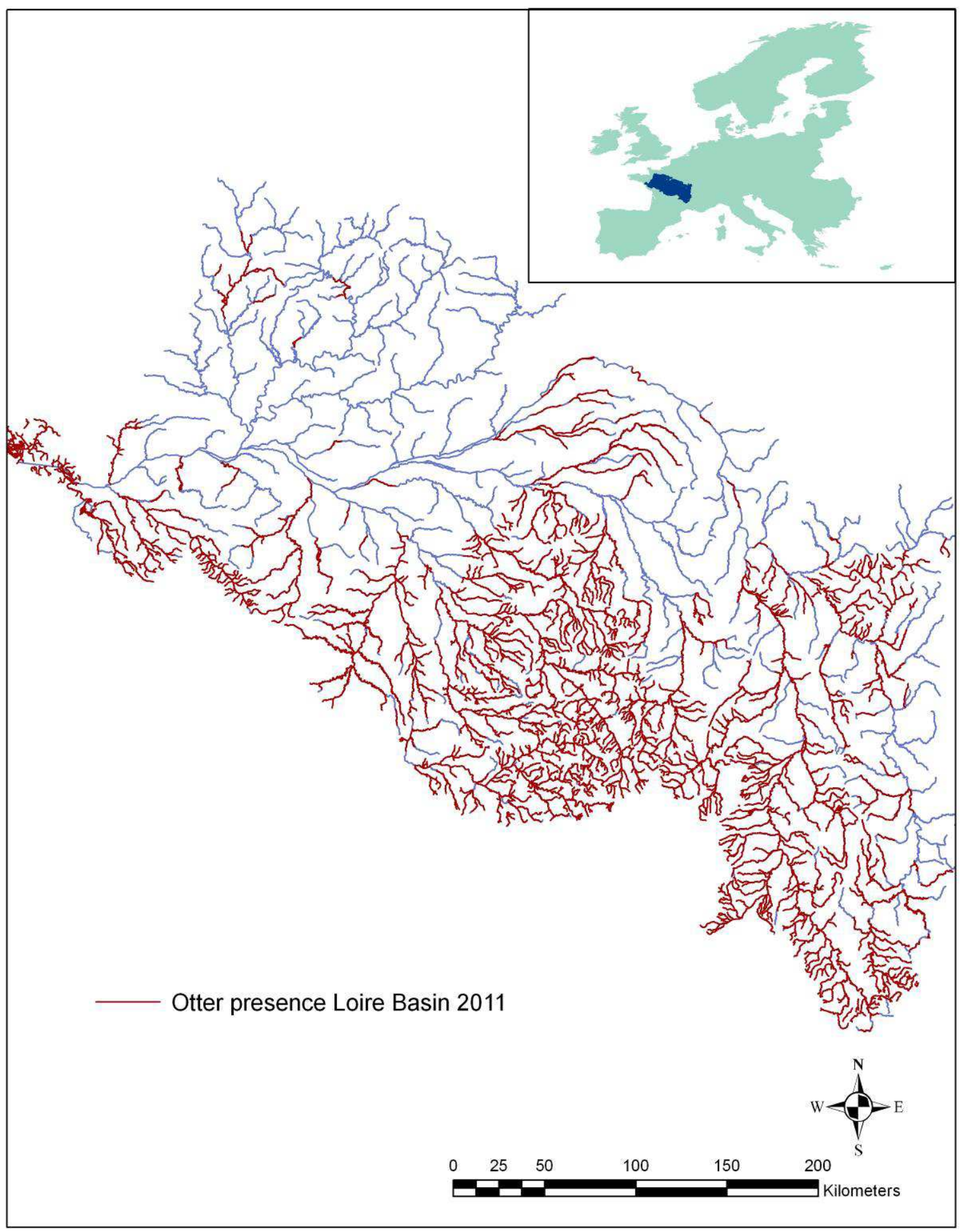

Figure 1. Presence of the European otter in the Loire river basin in 2011 
507

508 Figure 2. Illustration of the constructed river network topographical structure of nodeconnector ranking for a river segment to neighbouring segments.

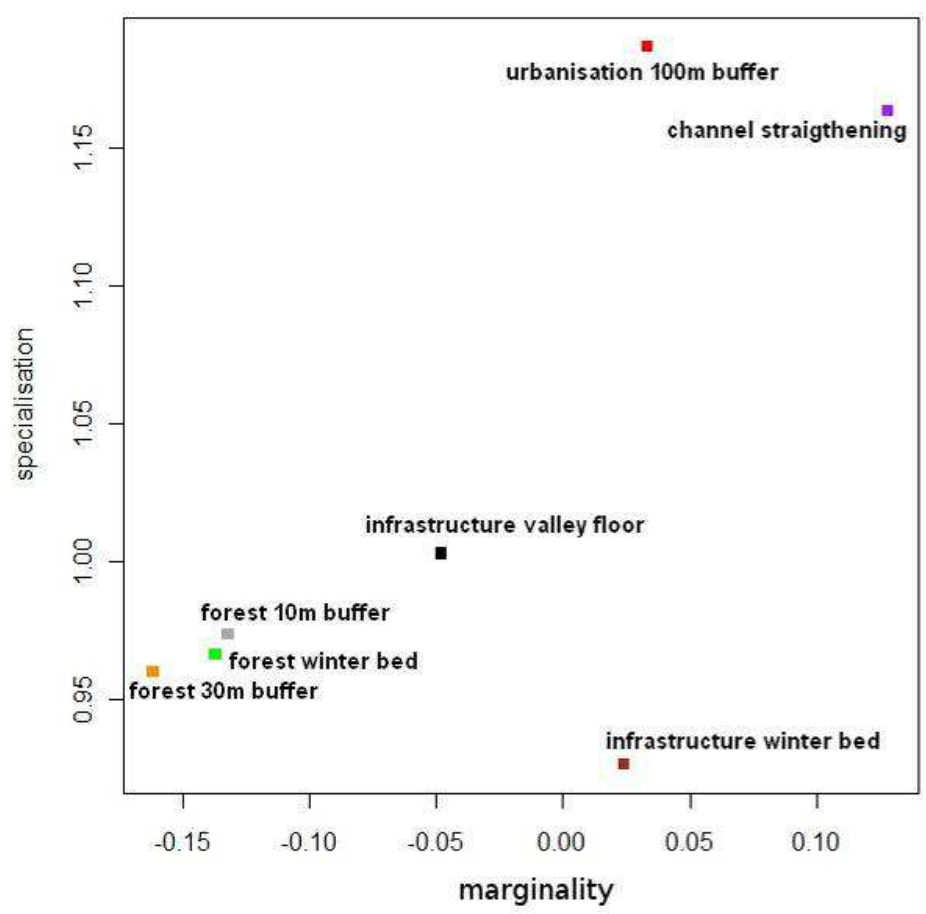

515 Figure 3. Ecological Niche Factor Analysis for the European otter. 


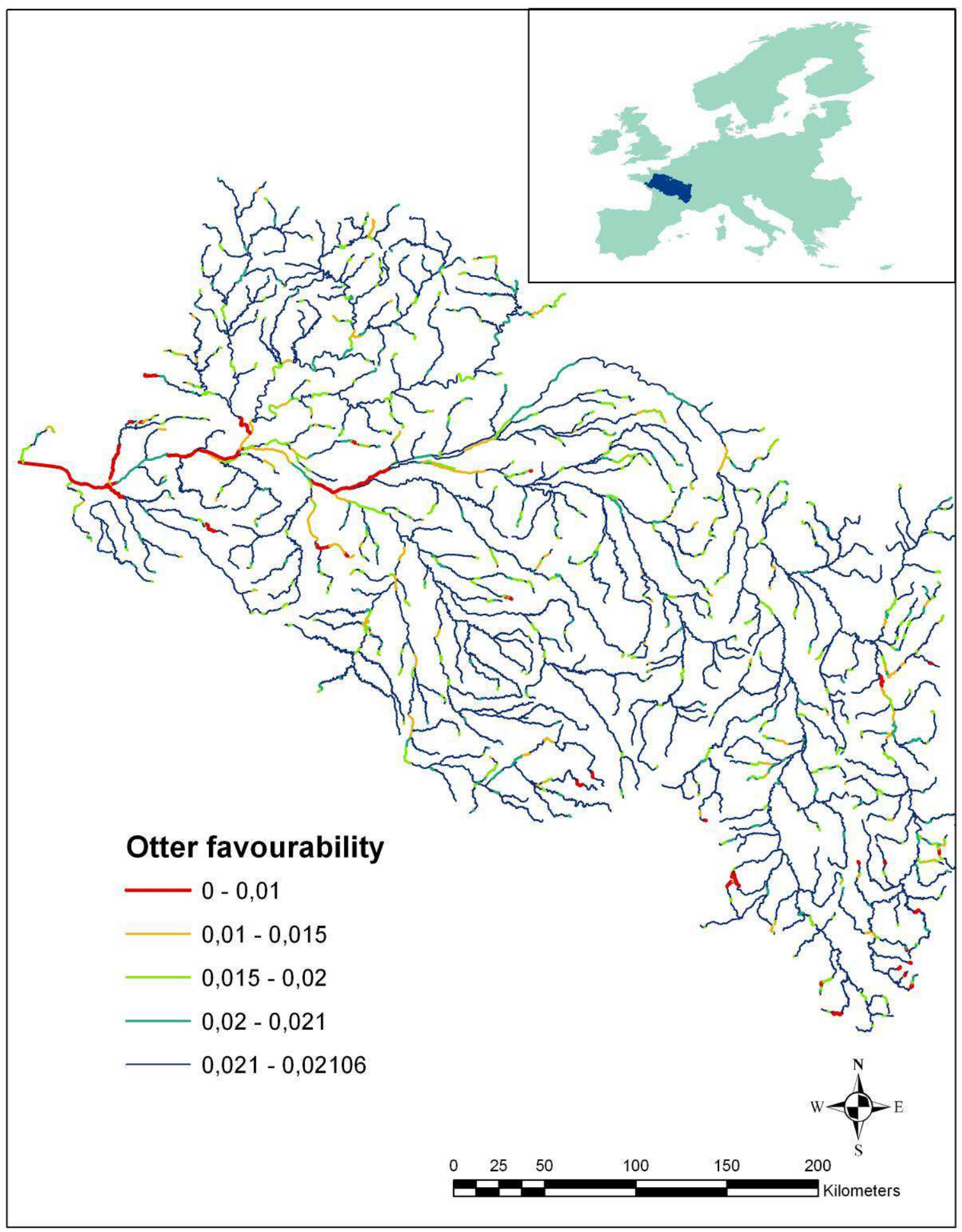

521 Figure 4. Otter favourability of river segments in the network of the Loire basin

522 (favourability values present contribution of individual segments in percentage to total 523 network). 
Author-produced version of the article published in Landscape Ecology (2013), vol. 28, $n^{\circ} 7$ The original publication is available at http://link.springer.com/ doi : 10.1007/s10980-013-9869-x

524

525

526

527 


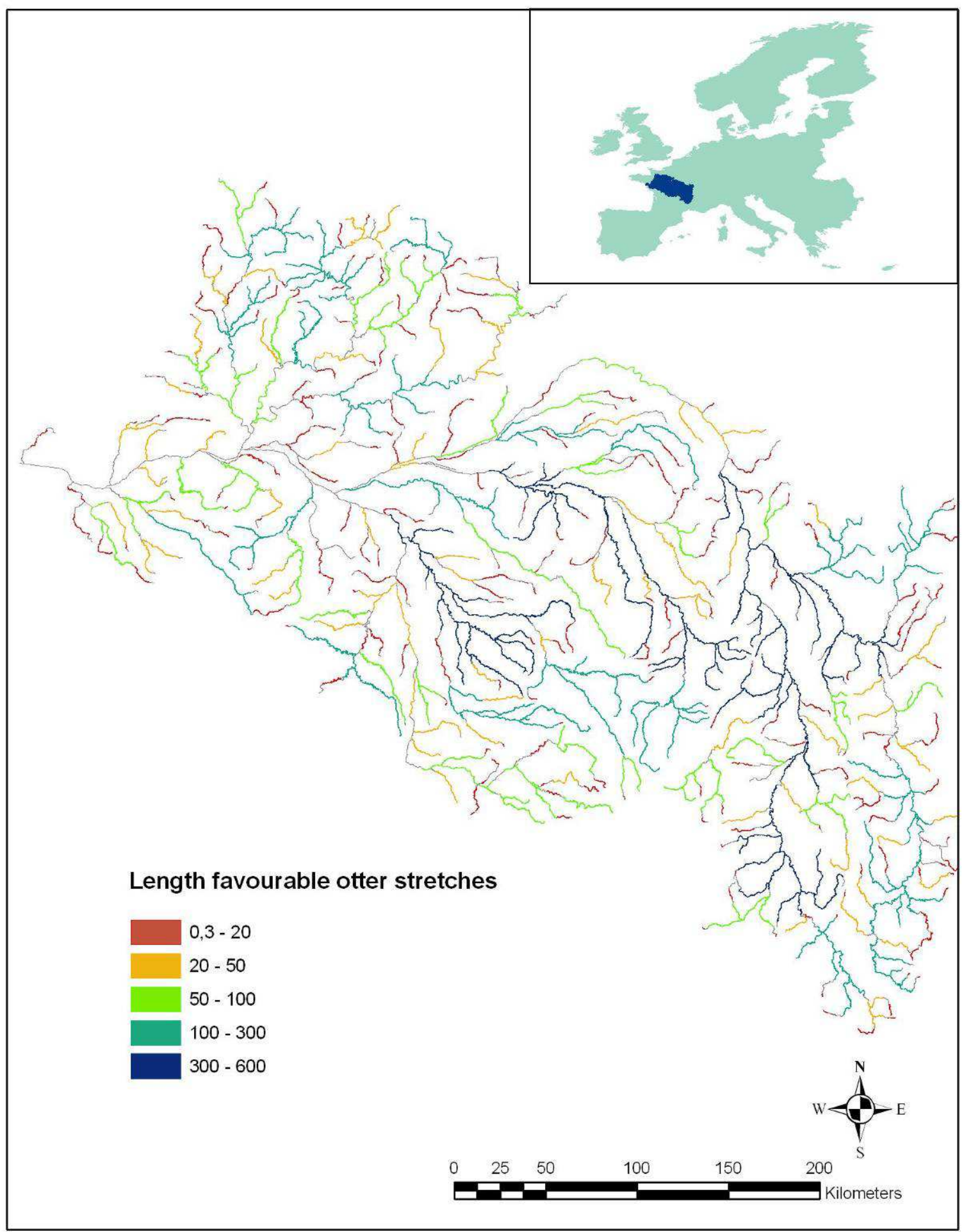

529 (a). 


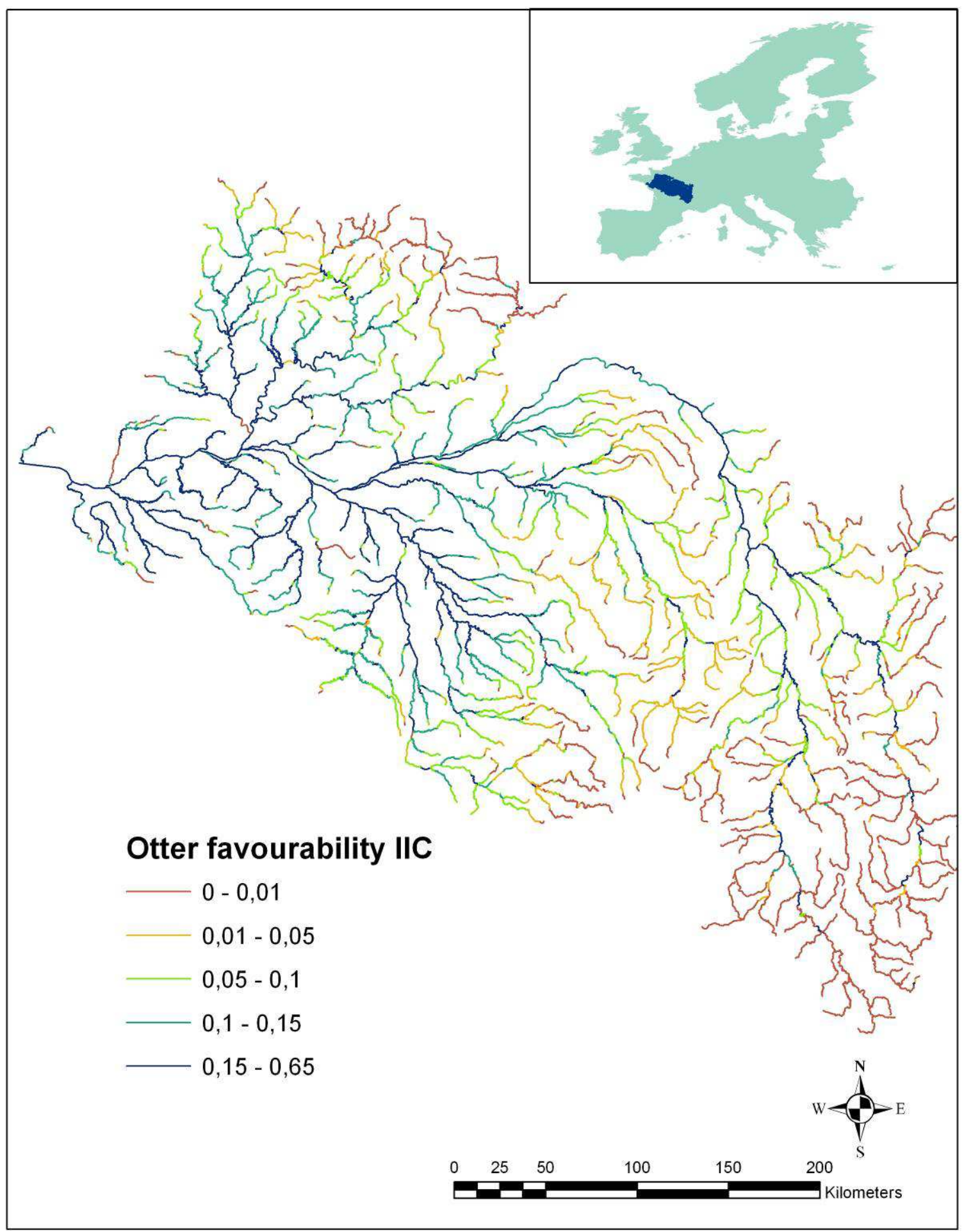

532 (b).

533 Figure 5. The ecological networks based on local habitat quality - with connection

534 distance $0-(a)$, and based on the Integral Index of Connectivity calculation for

535 connection distance 5 (b). The figure 5a presents length $(\mathrm{km})$ of continuous favourable 
536 habitat for otter (favourable segments gathered with barrier threshold $2 \mathrm{~km}$ ) in the Loire

537 basin (colours indicate $\mathrm{km}$ of linear in classes). Figure $5 \mathrm{~b}$ presents the Integral Index of

538 Connectivity calculated dIIC network values. The dIIC values give an immediate

539 ecological network qualification (the values present contribution of individual segments in

540 percentage to total network) and representation.

541 


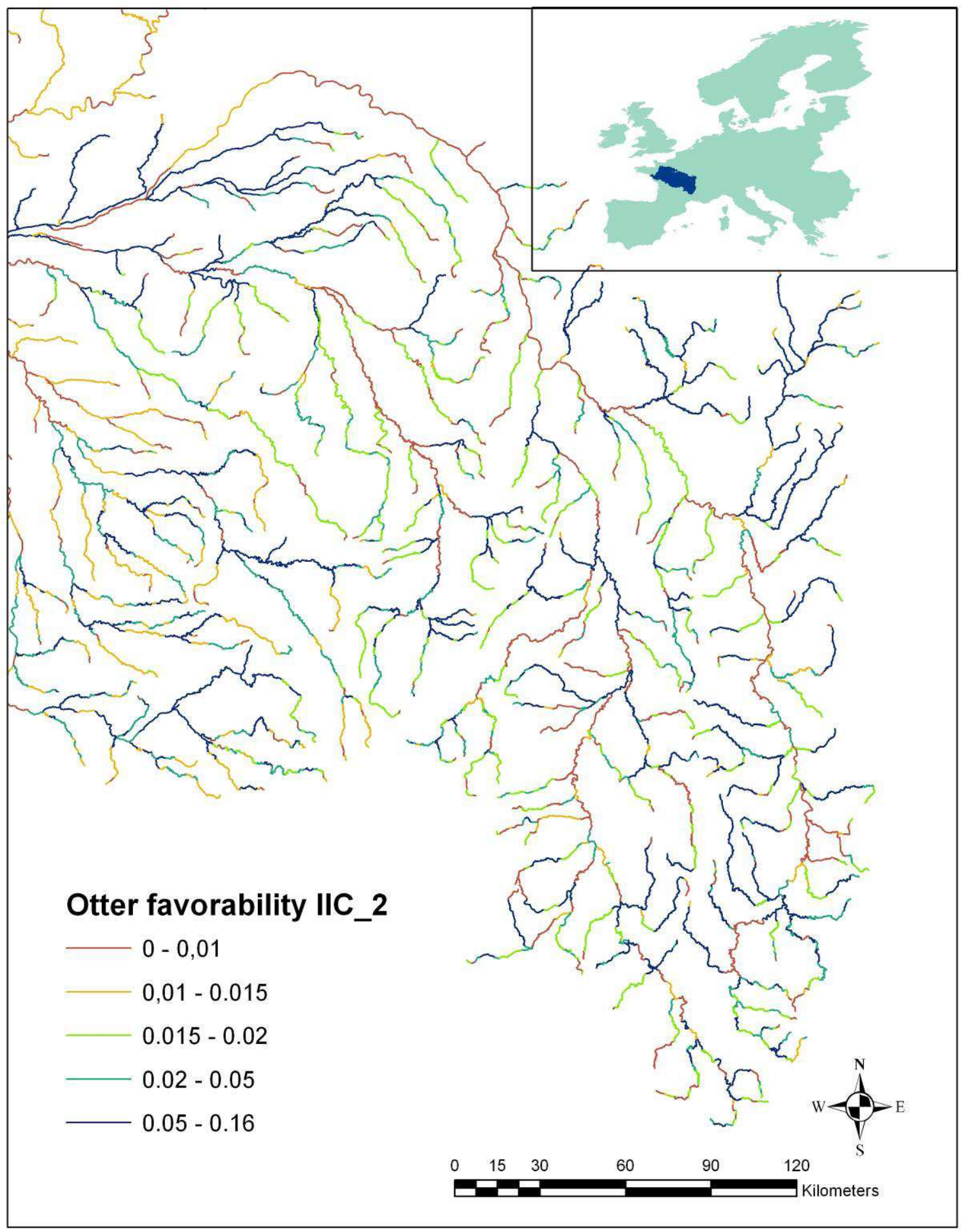

544 Figure 6. The ecological network qualification based on the Integral Index of

545 Connectivity calculation for connection distance 2 for the central and upstream part of 546 the Loire River basin. 
Author-produced version of the article published in Landscape Ecology (2013), vol. 28, $n^{\circ} 7$ The original publication is available at http://link.springer.com/ doi : 10.1007/s10980-013-9869-x

548 